\title{
Contradiction, collaboration and criticality: Researching empowerment and citizenship in community-based arts
}

\section{Alison Rooke}

\section{Setting the Scene: community arts and cultural policy}

This chapter examines the work of two London-based community arts organisations: London Bubble Theatre and the Stream Arts which were selected as ESRC Take Part case studies ${ }^{1}$. The work of these organisations demonstrates how arts organisations and arts practitioners are well placed to explore the themes of social action and community empowerment. Through participative and socially-engaged practice they create highly relevant and aesthetically sophisticated local projects which stimulate people to take an active and critical role in civic society. Both of these research studies were presented to the Taking Part conference/ 'un-conference', contributing to discussions with colleagues from arts organisations, Third Sector organisations and academics from the UK and beyond, internationally, as the previous chapter has already explained.

These Take Part case studies offer lessons regarding the relationship between the 'community arts' sector and the people they work with and the role of research in these organisations. As well as examining the social significance of these projects, this chapter also takes as its focus the ways these projects might be evaluated as part of a wider consideration of the evaluation regimes that the community arts sector is subject to. The chapter argues that whilst the community arts sector is required to evaluate the impact of their work in order to evidence the social impact of their work and in that process demonstrate their accountability to

\footnotetext{
${ }^{1}$ The Take Part Case Study reports are available from http://www.gold.ac.uk/cucr/research/
} 
funders, this limits the potential for research and collaborative critical reflective practice within these organisations. The case studies also illustrate some of the debates regarding the relationship between the aesthetic dimensions of 'participative' 'collaborative' or 'socially engaged' art practice and community empowerment. In addition, they point to the value of developing a critical and collaborative research culture as a way of developing and reflective practice amongst organisations and their participants.

The chapter highlights the dangers of an evaluation framework which foregrounds versions of active citizenship which are compliant and conservative and argues for the value of the spaces that such projects offer, making apparent social concerns, and creating convivial and playful spaces for critical reflection (Freire 1970). Evaluation frameworks which accompany sources of funding can underestimate and distort the critical and creative work of community arts organisations. Due to an emphasis on the impact on individuals, they also overlook the often less tangible dimensions of their work such as community development and active citizenship. The case study research focussed on how arts organisations encourage and develop active citizenship and community empowerment and the ways their practice differs from, or complements, community development work and other initiatives that have community engagement as a central logic.

Historically community art projects have often been based in deprived areas, with a community oriented, grassroots approach ${ }^{2}$. One of the broad aims of the community arts movement has been one of opening up the means of cultural production and expression to all. This participative ethos was a critique of an

\footnotetext{
${ }^{2}$ See Tiller, C, this volume for further discussion of the history of community arts in the UK.
} 
experience of art mediated through the acquisition of cultural capital and distanced spectatorship and contemplation, in the recognition that art can provide both mode of expression and a space of critical pedagogy. As Tiller argues (this volume) under New Labour cultural policy this sector found itself delivering the government agenda rather than providing the voice of criticism and dissent. Since the 1990 s in the UK, under the New Labour government national and local policy makers and funders recognised the value of the work of the arts sector3. Arts organisations and artists have been seen as important players in the revitalisation of communities and a project of social inclusion.

A substantial body of academic work made a strong case for the social impact of the arts. Research by Landry et al (1996), Galloway (1995) and Matarasso (1997) established a case for the social impact of the arts (Lynch 2011). Matarasso's study provided the earliest authoritative evidence of the impact of socially-relevant arts practice. This body of research was also important in establishing a workable methodological framework for social impact assessment, providing practical evaluation instruments to guide public policy planning and development, clearer definitions of the social benefits of the arts, and for the first time coherently bringing these matters to the attention of policymakers and the arts funding agencies. Concurrently arts practice became increasingly subject to modes of evaluation which employ quantitative matrixes and systematic toolkits (Belfiore 2004, 2009, 2010, 2010a).

\footnotetext{
${ }^{3}$ The Cultural Industry Task Force and PAT 10 investigation, (2001) as well as the work of Comedia (and especially Landry and Matarasso) were key landmarks in this argument. Within this policy landscape the arts are seen as instrumental in creating a knowledge economy and a skilled workforce. However, while the value of the cultural and creative sector to physical and economic regeneration has been extremely widely recognised (in part due to high profile physical projects like the Baltic Exchange in Newcastle, the new Laban building in Deptford or the Tate Modern at Bankside.
} 
This growing body of research was timely, coinciding with the election of the New Labour government, new funding streams for the arts (such as the Lottery and Single Regeneration Budget, SRB) and a technocratic desire for systematic performance measurement within the new 'audit culture' (Power, 1999, Strathern, 2000). Less central to this sector, and often totally overlooked in debates regarding the impact of the arts, are questions about the kind of work art should do. A hegemonic understanding of art as a social utility elides the radical histories and potential of participatory and socially engaged art forms. As George Yudice has argued, the meanings and effects of culture are produced expediently through of a set of institutional preconditions and processes.

The "bottom line" is that cultural institutions and funders are increasingly turning to the measurement of utility because there is no other accepted legitimation for social investment. In this context, the idea that the experience of jouissance, the unconsealment of truth, or deconstructive critique might be admissible criteria for investment in culture comes off as a conceit worthy of a Kafkaesque performance skit. Yudice 2003: 16

Within the disciplines art practice, education, curation and cultural policy a number of critics are concerned with the ways that art potentially provide an imaginative and critical space to address and engage with public issues that are defined by those directly impacted by them. Here arts participation has radical potential as a part of a project of social justice and societal change (Negri, 2011, Bruyne and Gielen 2011). Partly in response to the perils of instrumentality within the field of arts education and curation this field of debate has focused on the extent to which socially-engaged and participatory practice should or should not be used to reach aims that are defined through social policy i.e. should art's purpose be increasing the skills/well-being of participants? Should it aim to improve ‘community cohesion', increase citizenship? Or should it offer 
opportunities to reflect critically and respond to the social situations which it intervenes in? Some of these debates propose the incorporation of social processes into definitions of art, claiming new forms of aesthetics informed by the 'relational' or the 'dialogic'. (Kester, 1998, Kester, 2004, Bourriard 2010). Others suggest that engaging in social fixing or filling gaps in the depletion of social service funding and community development organizing decreases the possibility for freedom, expression and creative autonomy (Bishop 2006)4. Others, still, argue that art could offer processes and practices of political autonomy in relation to social problems, that is that art can address social problems, but not in ways that necessarily bring about behavioural changes defined by the state, the corporation or other social bodies not directly involved in the day to day lives of those most impacted by inequality and social injustice (e.g. reducing the number of people on social welfare or developing well behaved compliant citizens). Drawing on histories of community arts in the UK in the 1970s, as well as from traditions of popular education deriving from Paulo Freire (1970), participatory social and artistic research (Borda, 1991) and the use of art by social movements, this latter tendency suggests that socially engaged art has the ability to address issues as they are defined by participants in a collective process, making use of artistic skills in order to change perceptions and social relations. It relocates the question of whether art is 'good' to whether it makes use of aesthetic, relationship-building and communicative properties to provoke political impacts that groups have defined as relevant and important. Within this spirit the Take Part case studies demonstrate the ways that the arts sector working with a participative ethos (which spans community arts

\footnotetext{
${ }^{4}$ (Clearly this mirrors debates within the community and voluntary sector regarding co-option or acquiescence of the community and voluntary sector under neo-liberalism (Craig et al, 2011)).
} 
organisations and the education departments of larger galleries etc) can encourage critical active citizenship. Simultaneously they demonstrate the regimes of governmentality that the arts sector specifically (and the Third Sector more generally) are subject to.

The policy landscape surrounding community arts is challenging. The UK's Coalition government's much criticised concept of the 'Big Society', emphasises 'social action, public service reform and community empowerment' volunteering and 'philanthrocapitalism' (Rutherford 2010). These are themes which have relevance for the community arts sector. However, when combined with an 'austere' financial climate in which philanthropic giving and corporate funding are expected to replace public investment they are less promising. These funding streams come with an increased emphasis on business planning and demonstrating cost/benefit analysis with an associated set of measurements, matrices and systematic toolkits that arts organisations will no doubt be compelled to respond to.

\section{The Case Studies: Stream Arts and London Bubble Theatre Company}

The two Take Part case studies have much in common. Both are located in South East London and have a long history of working with local communities in localities which have been transformed due to large scale urban regeneration. London Bubble's premises which sits close to the river Thames, is surrounded by gentrified post-industrial 'loft apartments' and gated communities sitting next to blocks of social housing which were built in the post war period following the destruction of street housing in extensive air raids. In the area that Stream Arts work in, the local area has also undergone extensive riverside regeneration. The 
Greenwich Peninsula in the Borough of Greenwich, once dominated by gasworks and a power station has undergone tremendous change during the 1990s' development after the area was purchased by English Partnerships (now the Homes and Communities Agency) and subsequently developed with the building of the Millennium Dome (now renamed the O2) new homes, a primary school, a retail park and community facilities such as a riverside path and ecology park to open up access to parkland along the river.

The first case study focused on London Bubble's Theatre Company and their intergenerational Grandchildren of the Blitz project which developed into a theatre production entitled 'Blackbirds'. This applied theatre project was selected as it offered a clear example of London Bubble's theatre making methodology, their intergenerational practice and the company's participatory ethos. London Bubble was established in 1972 with a mission to tour shows to audiences in outer London. Originally the company used a tent theatre format, then, as it evolved it added a community projects team and delivered participatory or applied theatre projects within community settings. Since 1998 the London Bubble Theatre has aimed to '[P]rovide the artistic direction, skills, environment and resources to create inspirational, inclusive, involving theatre, which shares stories that animate the spaces of the city and the spirits of its citizens'. Their work is underpinned by the belief 'that every Londoner should have access to creating, participating in, and enjoying theatre - to communicate, connect and inspire' (taken from London Bubble website). London Bubble is an interesting case study as they attract a great deal of longitudinal participation from diverse participants. Their work engages Londoners as participants, practitioners and audiences. So, for example, their current activities are inclusive to all age groups and intergenerational interaction plays a key role in the development of their programmes. 
As a theatre company that has been established since 1972, they have been attracting longitudinal participation on a variety of levels.

This research was concerned with the quality of this participation and understanding. The Grandchildren of the Blitz applied theatre project is a clear example of London Bubble's theatre making methodology and their intergenerational practice. Planning commenced in 2009, work with participants commenced in May 2010 - to continue to January 2012. This intergenerational research-led participatory project set out to explore the local experience of the Blitz period of the Second World War in Bermondsey, Rotherhithe and Deptford, and to uncover the experiences and stories of those who lived through the Blitz. London Bubble, like Stream Arts have had a long-term creative engagement with local communities in areas undergoing urban development and regeneration. The Grandchildren of the Blitz project investigated memories of a period when the docklands and the surrounding areas, where London Bubble is based, were a key target for wartime bombing raids. During the Second World War many of the houses, buildings and some entire streets were completely destroyed. As the area has been developed over the years and subject to large- scale capital-led regeneration and gentrification in the 1980 s and 9os the damage to this largely working class landscape is hidden and forgotten today. For the Grandchildren of the Blitz project local children were trained in oral history interview methods, and then, accompanied by a 'middle generation', interviewed local older people who had lived through the Blitz. This research-led process built on interviews conducted by children with elders, who themselves had been children during the Blitz. The interviews were recorded and transcribed.

The extensive research and development phase culminated in a play Blackbirds, written by Simon Staring, in response to the research and workshop phase of the 
production. This culminated in a performance of a play entitled Blackbirds over six nights at Dilston Grove, an arts building within a former Mission Church on the edge of Southwark Park. The play toured in the autumn of 2011. This case study provides an example of the inventive and inclusive methods that go towards creating an applied theatre production. The final performance of Blackbirds performance was the result of a process that included participative workshops. The second case study, Stream Arts, is a creative production agency based in North Greenwich since 1985. Stream Arts bring together art practice and local people through playful and collaborative projects. This case study research focuses on two Stream Arts commissions: Now Hear This by The Holy Mountain and $A-X$ by the artists' gethan\&myles. Both projects were part of Stream Arts' Peninsula programme of commissions that aim to engage local communities in creative responses to the political, economical and physical changes of the Peninsula Ward of the London Borough of Greenwich. These commissions were examples of art which brought together research-led arts practice, local opinion and the politics of regeneration in particularly interesting ways. Now Hear This was the first commission in the Voices strand of Stream's Peninsula programme.

This strand of projects were focused on giving voice to people living and working in the area through a variety of media and stimulating debate around issues of local concern. For their commission with Stream Arts, Holy Mountain created a phone line whereby residents of the Peninsula could call in with dispatches about

\footnotetext{
${ }^{5}$ Stream Arts were being previously called Independent Photography. Independent Photography were a local community arts resource, carrying out audio and visual work in partnership with various arms of the local authority such as Greenwich Youth and Play Services, Children's Services, Safer Neighbourhood Teams, and the Looked After Children Team. Stream Arts were rebranded in 2008, marking a shift in Steam Arts mission, from being a community resource whose focus was working with young people and local people, addressing social inequality, to a being an arts agency commissioning location-specific, artist-led participatory public and collaborative art project. In the period since the research was completed Stream Arts are under new management
} 
issues related to the area of Greenwich. They also ran parallel activities, like walks around the local area, or meetings, like the event 'A Local Conversation', when local residents were invited to have a discussion about some of the issues raised in the phone calls. A-X was conceived by gethan\&myles in response to Stream's brief, 'Performing Social Space'. Stream were looking for a project which was innovative in its approach to working with local residents to elicit perceptions of the local area, and which would explore the potential of the varied physical environment of the Peninsula as a site for staging performative events and interventions. For this commission the artists visited locations around the Peninsula (parks, schools, the street, or libraries among others), and invited local residents of all ages and backgrounds to playfully reflect and muse upon Greenwich Peninsula and surrounding East Greenwich area. gethan\&myles also collected statements from documents regarding the local area produced by official entities, such as the local authority, developers, or housing agencies. The statements were edited and displayed on two solar powered DotMatrix LED signs (usually found on highways announcing traffic disruptions). The intention was to place these in four different locations in Greenwich over four weeks.

This motif of conversation, found in the first case study, was also apparent in the A to $\mathrm{X}$ project. A to $\mathrm{X}$ can be understood as a conversation between the two signs. Sign 'A' represented the 'official voice' of the Greenwich Peninsula, displaying statements taken from road signs, documents produced by the local authority, developers promotional material, and so on, whereas sign ' $\mathrm{X}$ ' represented the 'local voice' of people, displaying the words of local residents that the artists gathered during their research. 
(A sign) It's like a unified voice. It's the general establishment recording. So it's the voice from official documents, or brochures. (...). In the A sign, it all sounds the same. Whether it is a developer, or (the council they have a very shared style of language. And representing the community, they cannot say "it's everything", they simplify it, and so they make this unified voice. Whether Xis the voice of hundreds of local people we talked to a very small cross section of people.

Interview with gethan\&myles, 2010.

The media chosen by the artist, LCD signs, directly referenced the physical changes to the local infrastructure and the disruption this causes local people.

[We're] taking something out from its context. People around here, they're used to see these signs in the context of giving bad news, saying this road is blocked, or there's gonna be delays... So taking them from the road and putting them here in this park with all the trees around, in this big avenue, with the graves of sailors from the Spital. So it's like this amazing kind of historic place, and then you have this weird kind of robotic thing...

Myles, from interview with gethan\&myles

As described by Stream Arts in their project publicity this was a project which 'gives voice to the residents of East Greenwich and the Peninsula through a poetic and witty intervention in the local landscape'.

Over the past three months gethan\&myles have talked to hundreds of people of all ages in East Greenwich and the Peninsula. Their words beautiful, sad, uplifting and funny - will be displayed on flashing signs in three different locations, as these commonplace pieces of roadfurniture are transformed into performative, sculptural objects.

A-X Press Release, Stream Arts 2010

By juxtaposing these two sets of voices in public space in the area, the artists aimed to show how Greenwich Peninsula has a wide diversity of opinions and a plurality of identities, and in this way aimed to create space for debate. Although Stream is not a community development organization they do a lot work which is similar to that of a community development organisations, in that they invite local 
people to come together, to take part in local research and debate, invite them to reflect on local processes, and so on.

In this context, the Critical Friends group is an important space of participation within Stream Arts. The 'Critical Friends' group, made up of local residents, was facilitated by Sophie Hope, an artist and academic 6 . This group ran regular workshops, edited a blog and compiled research materials into a Critical Friends magazine produced every four months through regular workshops which provided sites for the writings, documentation, performances and presentations created by Critical Friends. Considering the large scale regeneration the area the organisation is located in, the scale of participation it allowed was somewhat limited. This was due to resources and Stream Arts' size. Furthermore the wider possibility of the development of an active and engaged community through the participatory artwork was also curtailed due to the loss of community development organisations in the area.

In the Peninsula we have really been able to build up a programme of kind of interconnected projects over the five or six last years. Things have hugely changed on the Peninsula, obviously. There was a lot of more community infrastructure when we started off. A lot of that has disappeared now through the folding of the programmes and through the economic crisis, which has seen a lot of the community workers in the area disappear. So it has not been a kind of neat progressive line of us being able to work in a consistent fashion, because the support has disappeared in lots of areas.

Interview with Stream Arts Director

\footnotetext{
6 See Hope.S. 2011 for discussion of the Critical Friends evaluative model. This model of participation is also highlighted in the(2011) Paul Hamlyn Foundation Report 'Whose Cake is it Anyway' as a model of "embedding local collaboration and developing individual capability for participation rather than 'empowerment-lite', the work becomes firmly situated in the organisation's locality and developed with the help of new, long-term community partnerships as 'critical friends'. (2011: 08)."
} 
The Critical Friends group was an important space of active citizenship both within Stream, as a space of participation, and within the local area more generally as it provided a space to reflect on arts commissions, artists' intentions and the role of art in urban change. At the time of the research their capacity was limited due to resources. This group had, to some extent, grown out of Stream's Peninsula programme in the recognition of the short term nature of arts commissioning practice whereby artists 'parachute' into an area and then leave swiftly at the end of a commission. As the Director discussed here;

[T] been one of the things we have tried to work against. Given the constraint that we are a very small organisation and considering the funding you need to actually build long term programmes. [W] hat you can achieve is obviously far greater over a long period of time than over a smaller period of time. You build up knowledge of the community, and you can involve the community over a longer period of time.

\section{Community Theatre and Active Citizenship.}

The case study research demonstrated some of the ways that arts participation can encourage and activate active citizenship. Many galleries and arts organisations are doing community development work, bringing together local communities through on going collaboration and what has been termed 'durational' practice (Doherty and O’Neill 2012) which aims to counter the transient short term ways that artists are deployed in social settings. London Bubble Theatre London Bubble is an excellent example of an organisation which provides multiple and flexible cultural spaces of participation where participants have the opportunity to enact, practice and develop active citizenship. London Bubble can be understood as an open and dialogical space which mirrors some of the ideals of citizenship discussed in this book. Participants and practitioners have been able to move within and through these spaces as they grow and develop their creative skills and their qualities as active citizens. These multi-facetted 
modes of participation have been central to the company's commitment to coproduction and collaboration. London Bubble is a flexible, open, welcoming organisation. New participants become part of an evolving group of community performers from diverse backgrounds, and are subtly 'inducted' into the culture of the company as they through the multiple spaces of participation that London Bubble offers. Participation in London Bubble is not circumscribed to a specific body, such as a consultative body, a user-group or a group of 'critical friends'. Rather, participation in London Bubble takes place on a variety of levels. Participants may begin to participate in an age specific resident group or through a specific production but they are not limited to these more 'formal groups'.

Participants experience London Bubble as open and responsive.

Bubble have tried to make themselves more open creatively, it's much more ambiguous, written through workshops, with the writer coming back with the scripts, the script getting changed the script getting changed.

The distinction between professionals and participants was distinct but it has changed. It has been eroded over time.

The way that Bubble reflects and listens is organic and involving. [I]t is a complex democracy.

Quotes from adult focus group

This was a strong theme in the focus groups conducted as part of the research. As stated by this long term participant who began taking part 'accidentally', as she explains here,

I came in sideways, I was asked to fill in. I was actually doing the tea and biscuits and then they said, 'Will you stand in for this part?' And I did it. And then they said 'you might be interested in coming to the Bubble'. And I came, and was part of the group for a long while. [] They always seem to provide challenges that people want. If you put the commitment in, if you want it, then things come your way, if you are up for it'. 
London Bubble was perceived as having a horizontal structure. Their 'open door' enabled people to participate in a way that was appropriate to their capacity and levels of comfort at the time, given their other commitments, ambitions and desires. This flexible space of participation and development has been one of the key factors in engendering the longitudinal participation that is the focus of this study. This was a strong theme in the focus groups when the research team asked participants to produce 'time lines' of their participation in London Bubble (see figures 1 and 3). Some adult participants who had began coming to Bubble as small children, brought along by their parents, had flowed in and out of the company as they grew, moved, entered formal education or training and returned as practitioners or participants. As described here

I was a London Bubble baby, before I was born it has always been constant thing in my life and has always been there for me what ever is going on in my life. When I was seven my parents broke up and a social worker took me to a workshop and I remember thinking this is what I want to do. My mother took me to the show that night 'Arabian Nights' it was my first theatrical experience. If it wasn't for London Bubble I would not be where I am now I would not have gone to university and studied theatre and I thank my parents for being supportive. My teacher told me you should not do theatre you will not get anywhere you should stay here a do maths and business studies I told them I would not do that. I knew I wanted to be myself and I wanted my placement to be at London Bubble. London Bubble supported me through my professional career and when I was a student. It has given me confidence; others have asked how did it give you confidence? I was a shy child I would hide behind my parents. I can be who I want to be, people ask how is it going at London Bubble and it becomes engrained in your life and it has etched onto other people in my life.

Female Participant and facilitator -Young people focus group 
The active citizenship that was being encouraged and developed within London Bubble was building the capacity of participants to take part as active citizens in spaces beyond London Bubble. The skills and attitudes which were being developed were having an impact as participants took their learning beyond the company. This was a particularly strong theme in the young peoples group where participants spoke of the ways that they had developed their active learning through taking part in Bubble and the ways that this had impacted on their wider participation as citizens.

I don't think I would have volunteered in activities at school if I had not come to London Bubble in the first place.

My mum has seen a change in me. I want to go out and work with young people involved in crime now. When you come to London Bubble all your worries are gone it makes you feel comfortable. It is a family unit. I have become a different person since I joined.

Young people focus group.

\section{From Community Arts to Creative Production}

Stream Arts also provided an excellent illustration of the relationships between arts and active citizenship. Clearly the two projects which the case study examined demonstrated the citizenship dimensions of their work. Stream Art's work also demonstrated tremendous potential in developing active citizenship. The tensions which arose in this case study research are instructive, though, in understanding the difficult position occupied by community arts organisations in collaborating with local stakeholders.

Now Hear This and $A-X$ provided a space where residents of Greenwich Peninsula and other participants could speak up and have their say about the issues of their everyday life in their local area. By collecting these experiences through participative workshops and sharing and displaying them creatively in the public realm, the artists of both projects opened up a collective space of 
critique and reflection for residents. This had value in itself, as an opportunity to think, reflect and enjoy oneself in the process. Both projects were an opportunity for participants to voice their opinions about the regeneration of the area and the changes it had brought to the physical infrastructure and social fabric of the Peninsula. Participants in both projects expressed nostalgia, or discontent with the development process: the privatisation of local space, the ways in which the population of the area was being imagined without consideration of the needs of families with children or older people.

There is nothing to do, 'cause the council don't think about the children too much. (...)They gotta pay attention to the children. Nowadays is all new built stuff, they don't build anything for the children. Just to get on the streets, you know, they are just bored, there's nothing to do. Kids have resorted into just walking into car parks and looking at fancy cars all the time. It's not very exciting.

I used the libraries in Greenwich for years. And East Greenwich library now, which has always been slightly run down, for all the length of time I've known it it's virtually falling apart. It's a beautiful building Victorian- and people care desperately about it. And however much is said, nothing is ever done.

Now Hear This Transcripts

Both projects offer examples about the ways in which socially engaged art, active citizenship and community empowerment issues dovetail. Clearly, these projects, by using playful and interactive methodologies offered enjoyable ways of involving local people in arts practice and democratic processes. This was in keeping with the aims of the Peninsula Programme and can be seen in earlier Peninsula projects7. They creatively and temporarily disrupted the dominant spatial meanings, controlled spaces and language of the Peninsula.

7 So for example, Christian Nold's Greenwich emotion map used mapping and biotechnologies to creatively show the emotional responses to changes in the local environment such as increased traffic). 
In this way Stream's projects were seeking to approach political and social issues from an oblique angle, with lightness of touch rather than through didactic messages. The cultural value of the art work was not found merely found it the spaces of participation it offered, but also in the ways that they intelligently mirrored spaces of democratic participation provided by the local authority and regeneration agencies (such as processes of consultation). In this way they aestheticized citizenship processes and the contradictions and failures of participatory democracy.

Stream Art collaborated with, and received funding from, local agencies invested in managing the social changes that accompany regeneration and promoting the positive aspects of urban change. Artists who seek to give voice to local residents open up opportunities to respond to and critique these processes though, however obliquely. The A to X project, for example, encountered a series of barriers to its full realisation. The proposed sites for the art work were refused and the text displayed was perceived as provocative and critical leading to the LCD signs being turned off and the text revised. This led to considerable frustration for the artists who felt that they were not able to honour their promises to the local people they had engaged in the creative process. It also resulted in Stream Arts staff being compromised in their commitments to a variety of stakeholders including, funders, local landowners, participants and artists.

This difficult position illustrates the tensions between engendering forms of active citizenship and community empowerment which is critical of the national and local agencies that exert power through ownership and funding. And it illustrates the difficulties facing arts organisations who seek to create spaces of empowerment and citizenship whilst in contractual relations with local agencies and a range of private and public funding bodies of those participants may be 
critical. This complex position is instructive when thinking about the kinds of active citizenship that can be engendered through these projects and the terms through which evaluation criteria led by notions of citizenship might be developed.

\section{Developing critical conversations through research}

As well as researching the case study organisations in relationship to citizenship and empowerment the research brief also included working with organisations to develop their research capacity and assist the organisations in developing methodologies for collecting data/evidence in relation to active citizenship and community empowerment.

It is also worth noting that both of the case study organisations were using participatory research in the development and evaluation of their creative practice. London Bubble employ a wide range of quantitative and qualitative research methods when evaluating their practice and evidencing the impact of their work on audiences and participants alike. This active interest in collecting and analysing research data informs the company's development and evolving practice. So for example, Grandchildren of the Blitz was an intergenerational research-led participatory project which set out to explore the local experience of the Blitz period of the Second World War in Bermondsey, Rotherhithe and Deptford, and to uncover the experiences and stories of those who lived through the Blitz. The younger participants researched the Blitz period and were trained in oral history Interview methods by the Imperial War Museum. This research informed the development of the script for the Blackbirds production. Within Stream Arts commissioned artists often conduct research, which is at times playful and inventive, informing and/ or being part of processes of community 
engagement. Stream Arts are also subject to evaluation scrutiny. Evaluative research offers a potential space for critical and reflexive discussion of the successes and learning from Stream's artists commissions. In parallel to the Critical Friends more formal evaluation is conducted by external consultants and researchers.

Each of these research settings offered different challenges to the research team. These, in turn, reflect wider inter-institutional relations between the Third Sector and the university and the tensions and possibilities associated with engaged critical academic research. Perceptions of the research differed amongst the various agents involved. For both organisations having academic research, conducted with theoretical rigor, carried out, about and with their organization was recognised as a valuable resource with added value. The research team also recognised that this kind of short term 'case study' work is viewed as part of the 'housework' of the academy, and not held in particularly high esteem within the matrices of performance through which university departments are evaluated ${ }^{8}$. The research teams conducted the research critically. They were aware that these organisations did develop active citizenship in valuable and interesting ways that were largely overlooked by their funders and supporters. They also recognised that finding ways to methodologically evidence citizenship and empowerment could be useful for the organisations themselves whilst also being yet another manifestation of the instrumentalisation of participative arts practice. For example, the Stream Arts projects Now Hear This and $A-X$ opened up a collective space of critique and reflection for residents whilst London Bubble provide

\footnotetext{
${ }^{8}$ The university is itself subject to the scrutiny of an evaluation framework which is subject to considerable debate regarding the measurement of its value. See http://www.ref.ac.uk/
} 
multiple opportunities for participants, volunteers and staff to exercise and active citizenship in their day-to-day work and through specific productions.

The contrasting institutional settings which surrounded the research led to some tensions though. Although London Bubble had 'matched' their case study funding with funding for an evaluation of the same project for 'added value', the expectations of the research teams' available time and resources were high and at times over ambitious. Past experiences of research at Stream Arts9 led to a misconception that the research would result in an evaluation report about two specific projects that were being delivered whereas in actuality the organisation itself and the projects it delivered were the subject of the case study. This led to tensions when some of the art work proved to be politically sensitive. The temporary closure and censorship of the A to X project, and subsequent events, were instructive in understanding the complex webs of institutional and funding relationships and the local relations of governmentality that Stream Arts sat within. This, in turn, pointed towards ways in which active citizenship was enabled in some ways and disallowed in others. These tensions were of great relevance to the research, pointing to the difficulties of combining a desire to collaborate with both local regeneration agencies who were investing in promoting the positive aspects of urban change, and artists who were seeking to give voice to local residents who may be looking to critique these processes, however obliquely. This led to moments of discomfort and considerable negotiation.

\footnotetext{
${ }^{9}$ I carried out several evaluations of several small Stream Arts projects prior to the Take Part research. These were not made public.
} 


\section{Conclusion}

In thinking about the relationship between arts and citizenship, it is worth considering what participative art does in relationship to civic and civil participation. Previous research into the social impact of participating in art has identified individual outcomes such as raised levels of self-esteem and confidence, an enhanced feeling of self-determination and control and skills development. This emphasis on individual impacts leads to the social and citizenship dimensions of this work being overlooked. The case study projects clearly demonstrated some of the ways that arts organisations do community development. It was significant that many of the people interviewed in the research did not see themselves as particularly active politically, nor did they express a desire to take part in more overtly political spaces of community participation. However, they did express a desire to take part in, and feel part of something that was both collective and local. The attraction and value of both organisations was often discussed in terms of the playfulness of these modes of participation. Participants in these organisations appreciated not needing to have a lot of specialist knowledge to take part. Instead value was placed on having fun, being silly and playful. Art participation offered respite from the seriousness of more formal spaces of citizenship (Indeed the seriousness of some of the discussions that took place in the interview and focus groups at London Bubble was often met with an element on tolerance, as participants took part before returning to the 'serious playfulness' (Rooke, 2010) of the theatre workshops which create the informal, and open and welcoming space that is London Bubble. Participative art provides a space to come together with others, whether informally or formally, a space to encounter difference, to collaboratively take 
part in the production of an art work, and realise one's potential. Participation in art can offer a social and cultural space for gaining skills, expressing opinions, challenging power structures. Playful, creative, and imaginative participation are inclusive and pedagogical (Rooke 2010) as they do not depend solely on verbal and written articulation which are requisite in some of the more formal spaces of citizenship participation. Instead, through playful and accessible practice, the perspectives of some of the most disadvantaged or silenced groups can be heard. At its best participatory and collaborative art can offer a space of critical pedagogy which addresses community empowerment and citizenship. Participation in arts praxis can be an exciting and liberating experience and alternative to cultural spectatorship. Citizens may decide for themselves what is to count as culture, express that sense of culture and, in that process, work out what kind of citizens they are. This creative and pedagogical space can also make apparent the constraints of social relations thereby opening up a space of critique and the production of critical knowledge. The projects described here, albeit in different ways, were bringing local people together in the process of creating of a temporary aesthetic communication, whether a play or an installation. In doing so these organisations were making possible both individual and collective experiences in which the familiar and local were being seen differently, as they entered the world of the symbolic and the imagination, however temporarily and saw everyday reality differently.

A consideration of the specific character of the practices of community and participatory arts needs to be foregrounded if we are to begin to understand both the complex ways that these projects develop active citizenship and community development alongside the significance of the aesthetic communication found in the art work itself. At a time when professional and state-funded community 
development is undergoing considerable change and a decline in funding, when cultural solutions to addressing social inequalities are employed expediently to solve social ills, there are critical conversations to be had between these sectors regarding the forms of governmentality to which they are each subjected. There is clear potential here for valuable collaboration and shared reflection between practitioners from these different sectors regarding the political, ethical and social tensions that their work explores and addresses. There is also a clear need for critical research and reflection which explore the possibilities of reclaiming evaluation as an informative, generative, critical and non-partisan activity in the context of contemporary social and cultural policy. In a political and economic climate which emphasises the need for empirical justification for monies spent on social interventions and the arts, the question of how to differentiate between evaluation which is an extension of 'cost benefit analysis' and evidence-based policy and that which is an opportunity for critical and collaborative reflection is pressing.

\section{References}

Belfiore, E. (2004) 'Auditing Culture: The subsidized cultural sector in the New Public Management', International Journal of Cultural Policy, 10.2.

Belfiore, E. (2009) 'On bullshit in cultural policy practice and research: Notes from the British case', International Journal of Cultural Policy, 15.1

Belfiore, E. (2010) 'Is it really all about the evidence? On the rhetorical aspect of cultural policy', paper delivered at the 2010 edition of the International Conference on Cultural Policy Research, 24-27.

Belfiore, E. and Bennett O. (2010a) 'Beyond the 'toolkit approach': Arts impact evaluation research and the realities of cultural policy-making', International Journal for Cultural Research, 14.2.

Bishop, C. (2004) 'Antagonism and Relational Aesthetics', October. 110, no. 1: 5180.

Bishop, C. (2006) 'The Social Turn: Collaboration and its Discontents' Artforum, Vol.44 Issue 6.

Bourriaud, N. (1998) Relational Aesthetics. Les Presse Du Reel. 
Craig, G, Mayo, M. Popple, K. and Shaw, M, Taylor M. 2011 The Community Development Reader. History, themes and issues. Bristol: Policy Press

Doherty, C., Paul O'Neill, P. (ed.), Locating the Producers: Durational Approaches to Public Art ,Amsterdam: Valiz, 2011

DeBruyne, P., Gielen, P. 2011). Community Art, The Politics of Trespassing, Amsterdam: Valiz

Fals-Borda, O., Rahman, M. A. (Eds.). (1991). Action and Knowledge: Breaking the Monopoly with Participatory Action-Research (1st ed.). New York: Apex Press.

Freire, P. (1970/2006) Pedagogy of the Oppressed. New York: Continuum.

Galloway, S. (1995) Changing Lives, the Social Impact of the Arts, Edinburgh: Scottish Arts Council.

Hope, S. (2011) Participating in the Wrong Way. London: Cultural Democracy Editions.

Kester, G. (2004) Conversation Pieces. Berkeley: University of California Press.

Kester, G. (1998). Dialogical Aesthetics: A Critical Framework for Littoral Art. Retrieved [12/03/11]

from:http://www.variant.ndtilda.co.uk/9texts/KesterSupplement.html

Landry, C. et al. (1996) The Art of Regeneration, Stroud: Comedia

Lynch, B. (2011). Whose Cake is it anyway; A collaborative e investigation into engagement and participation in 12 museums and Galleries in the UK. London: Paul Hamlyn Foundation. [Available from: http://www.phf.org.uk/page.asp?id=1417]

Matarasso, F (1997) Use or Ornament? The social impact of the arts. Stroud: Comedia.

Negri, A. (2011) Art and the Multitude. Cambridge: Polity Press.

Rooke, A. (2010) Experiments with Form (in) The Cat Came as a Tomato - in Conversations on Play and Contemporary Art Practice. South London Gallery, London.

Rooke, A. (2011) Taking Part Case Study: London Bubble Theatre. Available at http://www.gold.ac.uk/cucr/research/

Rooke 2011b Taking Part Case Study: Stream Arts. Available at http://www.gold.ac.uk/cucr/research/

Social Exclusion Unit, Policy Action Team 10 London: DCMS, 2001. 
Power, Michael (1999) The Audit Society: rituals of verification. Oxford: Oxford University Press

Ross, A (2009) Nice Work if you can get it. Life and Labour in Precarious Times. NYU Series in Social \& Cultural Analysis).

Rutherford, J. (2010) ‘Labour’s Good Society', Soundings (46) 6-17.

Strathern, M (2000) Audit Cultures. Anthropological studies in accountability, ethics and the academy. (2000) London: Routledge. 